\title{
GMR
}

\section{Silencing miR-181a produces neuroprotection against hippocampus neuron cell apoptosis post-status epilepticus in a rat model and in children with temporal lobe epilepsy}

\author{
L. Ren ${ }^{1 *}$, R. Zhu ${ }^{2 *}$ and X. $\mathbf{L i}^{1}$ \\ ${ }^{1}$ Department of Pediatric Neurological Rehabilitation, Nanyang Central Hospital, \\ Nanyang, China \\ ${ }^{2}$ Department of Nursing, Nanyang Medical College, Nanyang, China \\ *These authors contributed equally to this study. \\ Corresponding author: X. Li \\ E-mail: beautifish415@163.com \\ Genet. Mol. Res. 15 (1): gmr.15017798 \\ Received October 10, 2015 \\ Accepted December 12, 2015 \\ Published February 19, 2016 \\ DOI http://dx.doi.org/10.4238/gmr.15017798
}

ABSTRACT. Epilepsy is one of the most frequent neurological disorders. Recently, the regulation of microRNAs was found to be associated with epilepsy, but the molecular mechanism by which microRNA influences epilepsy process remains to be unveiled and the development of microRNA-based therapy requires more intensive research. In this study, five microRNAs with potential relevance to epilepsy were initially chosen: miR-132, miR-146a, miR-181a, miR-34a, and miR-124. Twenty-five children who were patients with epilepsy were selected as subjects to obtain tissue samples for the study. The miRNA-181a, which represented the most increased fold-changes in clinical samples, were then selected for further function study in mouse model. The temporal lobe epilepsy (TLE) model, along with lithium-pilocarpine-induced status epilepticus (SE), was established in Sprague-Dawley rats. The antagomir of miR-181a was used to determine the role of miR-181a in cell apoptosis. Analyses 
were conducted to determine the expression levels of miR-181a, neuronal apoptosis in post-SE, and activated caspase-3. We found evidence of significant time dependent up-regulation of miR-181a amongst post-SE rats and TLE on $24 \mathrm{~h}(4.47 \pm 0.35), 7$ days $(4.85 \pm 0.53)$, and 2 weeks $(5.66 \pm 0.64)$. Experiments with the miR-181a antagomir showed that this particular miRNA led to the inhibition of the protein expression of caspase-3, and was up-regulated in the course of seizure-induced neuronal apoptosis. This study provided evidence that targeting miR-181a leads to a neuroprotective response and is linked to an increase in the activation of the caspase- 3 protein. These findings suggest that miR-181a may serve as a promising therapeutic target for epilepsy.

Key words: MicroRNA; Epilepsy; Hippocampus; Apoptosis;

Status epilepticus

\section{INTRODUCTION}

Epilepsy affects over 50 million people around the world and is the second most frequently occurring neurological disorder (Jallon, 2002). Medically intractable epilepsy is a common condition among children. The tragic consequence of this condition is its effect on the brain, causing recurring seizures throughout the person's life (Huttenlocher and Hapke, 1990; Berg et al., 2006). Neonates and infants are at the highest risk of developing seizures. The predominance of new seizure disorder diagnoses occurs at these ages (Liu et al., 2013; Li et al., $2014 b$ ). It is during this period of rapid growth and synaptogenesis that seizure susceptibility is greatest due to the natural excitability of the brain at this age. The treatment of epilepsy, which aims to reduce the duration of seizures, is related to neuroprotection (Arzimanoglou et al., 2002). The imbalance between the inhibitory and excitatory processes is thought to be the reason for the higher rate of epileptogenesis during childhood. Patients who have inherited forms of either epilepsy and epileptogenic malformation of cortical development will experience seizures early in life. The relationship between miRNAs and epilepsy is currently a dynamic and growing field of research. Until now, studies have focused primarily on the functions of brain-specific miRNAs following status epilepticus (SE) in both mice as well as samples from patients with temporal lobe epilepsy (TLE). The body of research to date has looked at the development and neuronal death associated with miRNAs during epilepsy and the expression and functional changes occurring during inflammation.

miRNAs are a class of endogenous small (18-24) nucleotides. They are long and noncoding RNAs, which function to regulate post-transcriptional gene expression by directing mRNA destabilization, translational repression, or a combination of the two (Hauser, 1995; Bartel, 2009). The improper functioning or expression of miRNAs has been related to several categories of pediatric diseases (neurological, chronic, and cardiovascular) (Omran et al., 2012a,b), and has also been proposed to play a role in the pathogenesis of epilepsy in the developing brain (Ashhab et al., 2013a,b; Peng et al., 2013). Part of the existing research has focused on exploring how targeting of different miRNAs involved in neurodevelopment can help to develop new therapeutic modalities. It has been shown that seizure-induced neuronal death in the adult brain occurs when miR34a, miR132, and miR181a are targeted. A neuroprotective effect is elicited when brain-enriched miR- 
134 is targeted, which has also been linked to the reduction of the severity of SE seizures as well as to the reduction in the frequency of spontaneous seizures at later stages in life (Jimenez-Mateus et al., 2011, 2012; McKiernan et al., 2012; Sano et al., 2012). It has also been shown reduced miR128 expression level in the postnatal neurons of mice, and causes increase in motor activity and fatal epilepsy (Tan et al., 2013).

Based on the above evidence, the hypothesis of this study is that chronic TLE leads to major alterations in the levels of miRNA in the brain and dysregulation of miRNA may be related to neuronal apoptosis and brain damage in TLE. To test these hypotheses, we investigated the expression of miRNA in the hippocampus of TLE rat model and patients with TLE. We used the activity of caspase-3 to assess the level of neuronal apoptosis in the hippocampus. Finally, we looked at the relationship between the differential expression of miRNAs and the level of caspase-3 activity.

\section{MATERIAL AND METHODS}

\section{Patient samples}

This study recruited twenty-five children with TLE who had undergone tailored temporal lobe resection for removing the epileptogenic area. The subjects were recruited from the Nanyang Central hospital and Zhengzhou Child hospital between February 2013 and February 2014. The parents of all patients were provided informed consent and agreed to surgical treatment and tissue sample collection in this study. This study was approved by the Ethics Committee of Henan Medical Association. All subject information was managed in compliance with the Helsinki declaration. Each subject underwent a detailed epileptological evaluation alongside a wakefulness/sleep electroencephalogram (EEG).

\section{Study animals}

The animals in this subject were composed of forty male Sprague-Dawley rats between 4 to 6 weeks of age, weighing from 200 to $280 \mathrm{~g}$, obtained from the Animal Unit at Zhengzhou University, China. The animals were treated according to the guidelines set out by the Animal Care and Use Committee at the Zhengzhou University. All rats were kept in a room with an alternating 12-h light/dark cycle at a temperature ranging from $18^{\circ}$ to $25^{\circ} \mathrm{C}$, with a humidity of 50 to $60 \%$. Both food and water were made available to the animals ad libitum.

\section{Experimental procedures for the SE and TLE model}

Lithium chloride $(125 \mathrm{mg} / \mathrm{kg}$ ) (Sigma, St. Louis, MO, USA) was injected less than a day (18-20 h) before the administration of $20 \mathrm{mg} / \mathrm{kg}$ pilocarpine (Sigma). Racine's scale was used to evaluate the severity of convulsions. Only those rats, which scored 4 or 5 on the Racine scale, were included in the study. SE (identified with a Racine scale score of 4 or 5) was defined as the beginning of a set of continuous generalized seizure activity lasting no fewer than $40 \mathrm{~min}$. Intraperitoneal pilocarpine administration $(10 \mathrm{mg} / \mathrm{kg}$ ) was repeated every $30 \mathrm{~min}$ for those animals who scored less than 4 on the Racine's scale or otherwise showed no seizure activity. The maximum volume for this injection was set at $60 \mathrm{mg} / \mathrm{kg}$. All subjects in the SE group receive chloral hydrate $(10 \% 3$ 
$\mathrm{mL} / \mathrm{kg}, \mathrm{ip}$ ) to terminate epileptic attacks. The control group received saline injections. The same environment was used to house all of the rats, which were observed from the time of the successful establishment of the SE model until their death. Rats were identified as having experienced TLE (3 months post-SE) through frequent spontaneous multiple seizures scoring at 4 or 5 on the Racine's scale. This group was identified either through direct observation or through a videotape. Seizures in some of the animals were confirmed by the use of EEG recordings, which showed high frequency and amplitude polyspike paroxysmal discharges. All animals were killed within a period of $5 \mathrm{~h}$ from their last spontaneous seizure. The mode of killing differed between animals. Chloral hydrate $(10 \%, 5 \mathrm{~mL} / \mathrm{kg}$, ip) was used to anesthetize some rats, which were subsequently decapitated. These rats had their hippocampus removed and frozen in liquid nitrogen. The other rats were first anesthetized and subsequently perfused with saline. This procedure was followed by placing hippocampus samples in a $4 \%$ formaldehyde solution.

Rats were killed at periods of $24 \mathrm{~h}, 7$ days, 14 days, and 3 months after SE was induced. Prior to being killed, rats were anesthetized with isoflurane. Next, the hippocampal tissues were dissected from the animals, which were frozen immediately. The next step was the RNA extraction of this tissue. This procedure was completed using the miRNA isolation kit (Ambion Inc., USA). The Agilent Bioanalyzer was used to test the quantity and quality of RNA and indicated the presence of 5, 5.8, and 18S bands.

\section{RT-PCR}

The TRIzol reagent (Invitrogen, USA) was used to isolate total RNA following the manufacturer protocol. Each sample of RT mixture contained $2 \mathrm{mg}$ of the RNA template as well as $2 \mu \mathrm{L}$ of miR-RT primers. This was mixed with $11 \mu \mathrm{L}$ RNase free water, $5 \mu \mathrm{L}$ RT buffer $5 \mathrm{X}, 0.5 \mu \mathrm{L} 2.5$ $\mathrm{mM}$ dNTPs, $1 \mu \mathrm{L}$ RNase Inhibitor $(40 \mathrm{U} / \mu \mathrm{L})$ (Fermentas, USA) and more RNase-free water to a total volume of $25 \mu \mathrm{L}$. Prior to use, the $11 \mu \mathrm{L}$ RNase-free water was mixed thoroughly and centrifuged at $4^{\circ} \mathrm{C}$. It was then incubated for a period of $10 \mathrm{~min}$ at $70^{\circ} \mathrm{C}$, and finally placed in an ice bath for $2 \mathrm{~min}$. The final volume samples of $25 \mu \mathrm{L}$ were incubated for $60 \mathrm{~min}$ at $42^{\circ} \mathrm{C}$, and then for $10 \mathrm{~min}$ at $70^{\circ} \mathrm{C}$. For the qPCR, we used the Platinum SYBR Green qPCR Super Mix UDG (Invitrogen) and the Applied Biosystems 7300 Real-Time PCR System (Applied Biosystems, Carlsbad, CA, USA). The qPCR was performed in triplicates. The qPCR steps were as follows: initial denaturation $95^{\circ} \mathrm{C}$ for $20 \mathrm{~s}, 40$ cycles $\left(95^{\circ} \mathrm{C}\right.$ for $10 \mathrm{~s}, 60^{\circ} \mathrm{C}$ for $20 \mathrm{~s}$, and $70^{\circ} \mathrm{C}$ for $10 \mathrm{~s}$ ), final extension $68^{\circ} \mathrm{C} 5$ min and hold in $4^{\circ} \mathrm{C}$. To calculate the relative expression levels for each miRNA, a comparative Ct method was used (Livak and Schmittgen, 2001). For internal control, the expression of the U6 small nuclear RNA gene was used.

\section{Western blot analysis}

All procedures were conducted following manufacture protocol (Abcam, CA, USA). Briefly, cells were centrifuged and lysed in solution. Proteins were loaded into the wells of the SDS-PAGE, along with molecular weight markers. The proteins were then electro-transferred to nitrocellulose membranes. The membranes were blocked for $1 \mathrm{~h}$ at room temperature or overnight at $4^{\circ} \mathrm{C}$ using $5 \%$ blocking solution, incubated overnight with a variety of primary antibodies at a temperature of $4^{\circ} \mathrm{C}$, and in horseradish peroxidase conjugated secondary antibodies (Cell Signaling Technology Inc., USA) for $1 \mathrm{~h}$ at room temperature. The expression levels of the targeted proteins were compared with those of the $\beta$-actin control (Santa Cruz Biotechnology, USA), based on the relative 
intensities of the bands. Band density was quantified in this study using the Quantity One V4.62 software (Bio-Rad, USA).

\section{Terminal deoxynucleotidyl transferase (TdT)-mediated deoxyuridinetriphosphate (dUTP) nick end labeling TUNEL apoptotic cell detection in formalin-fixed and paraffin-embedded tissue}

TUNEL, which detects DNA fragmentation resulting from apoptotic signaling cascades, was used to determine the neuronal apoptosis following manufacturer protocol (Bio-Rad). Briefly, the paraffin-embedded tissue sections were rehydrated and treated with proteinase $K$ to deparaffinize them. Then, the specimen was permeabilized with acetone and the endogenous peroxidases were inactivated with $3 \% \mathrm{H}_{2} \mathrm{O}_{2}$ in methanol. TUNEL-positive cells were defined as those demonstrating blue-purple nucleic staining. Microscopic detection (Nikon, Japan) under 40X magnification was followed after equilibration and end labeling in 5 randomly selected visual fields for each section.

\section{Data analysis}

All data are reported as means \pm standard deviation from three independent tests. Statistical analysis was completed using the SPSS 13.0 software package. One-way ANOVA comparing multiple groups was conducted $(P<0.05)$.

\section{RESULTS}

\section{Literature research and $\mathrm{qPCR}$ confirmation for candidate miRNA in patients with TLE and rat model}

We selected five microRNAs with potential relevance to epilepsy by literature search for 'brain-enriched miRNA' or 'glioblastoma-related miRNA': miR-132, miR-146a, miR-181a, miR-34a, and miR-124. The altered expression of miRNAs was confirmed by quantitative RT-PCR. As seen in Figure 1, the expression levels of miRNAs were all up-regulated in rat TLE model (fold-change: $1.75 \pm 0.09$ for miR-132; $2.34 \pm 0.14$ for miR-146a; $1.78 \pm 0.21$ for miR-34a; $2.75 \pm 0.23$ for miR$181 \mathrm{a} ; 2.46 \pm 0.06$ for miR-124, Figure $1 \mathrm{~A}, \mathrm{P}<0.05)$ and patient samples $(1.85 \pm 0.19$ for miR-132; $1.57 \pm 0.09$ for miR-146a; $2.00 \pm 0.16$ for miR-34a; $2.15 \pm 0.08$ for miR-181a; $1.96 \pm 0.35$ for miR124, Figure 1B, $\mathrm{P}<0.05)$.

\section{miR-181a expression at post-SE and miR-181a antagomir outcomes}

The expression results of miR-181a are shown in Figure 2A. It was found that miR-181 had significantly increased in the hippocampus of post-SE rats at 1 day $(4.47 \pm 0.35), 7$ days (4.85 $\pm 0.53)$, and 2 weeks post-SE $(5.66 \pm 0.64)$. This was followed by a decrease at 3 months post-SE $(2.75 \pm 0.31)$ in the frequency of TLE $(P<0.05)$. Despite this decrease, the level of miR-181 was still considerably higher than that of the control sample. miR-181a antagomir had significantly reduced the expression of miR-181a 7 days post-SE in the rat hippocampus $(2.77 \pm 0.36)$ compared to the miR-181a antagomir control group (4.76 \pm 0.54$)$ (Figure 2B, $\mathrm{P}<0.05)$. 
A

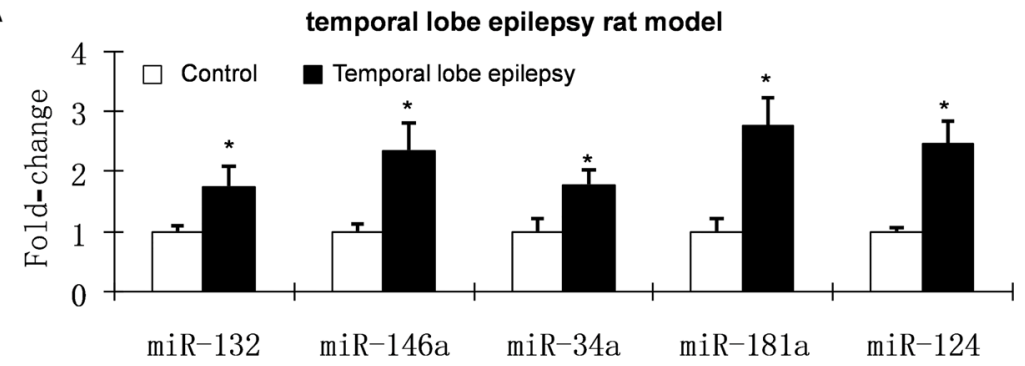

B

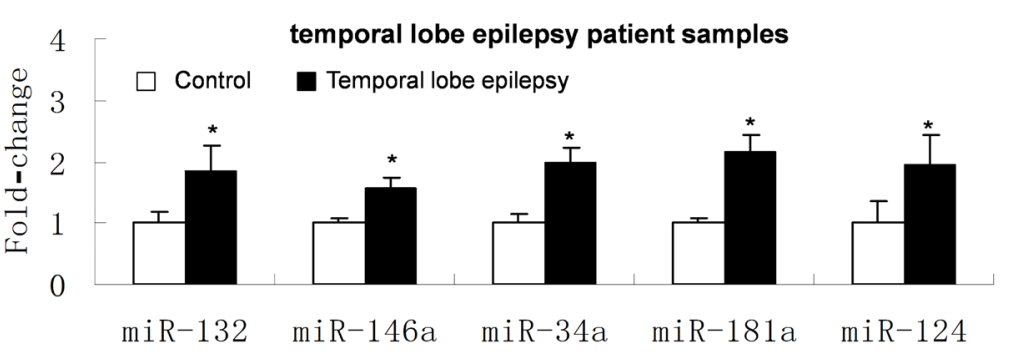

Figure 1. Quantitative real-time PCR validation of miRNA expression. Five differentially expressed miRNAs (miR146a, miR-181a, miR-34a, miR-121, and miR-132) derived from (A) the temporal lobe epilepsy (TLE) rat hippocampus and $(B)$ patient samples. Data are reported as means $\pm S D$ from triplicate tests, ${ }^{*} P<0.05$ compared to control; $N=10$ for each experimental rat group; 25 patients and 11 controls.
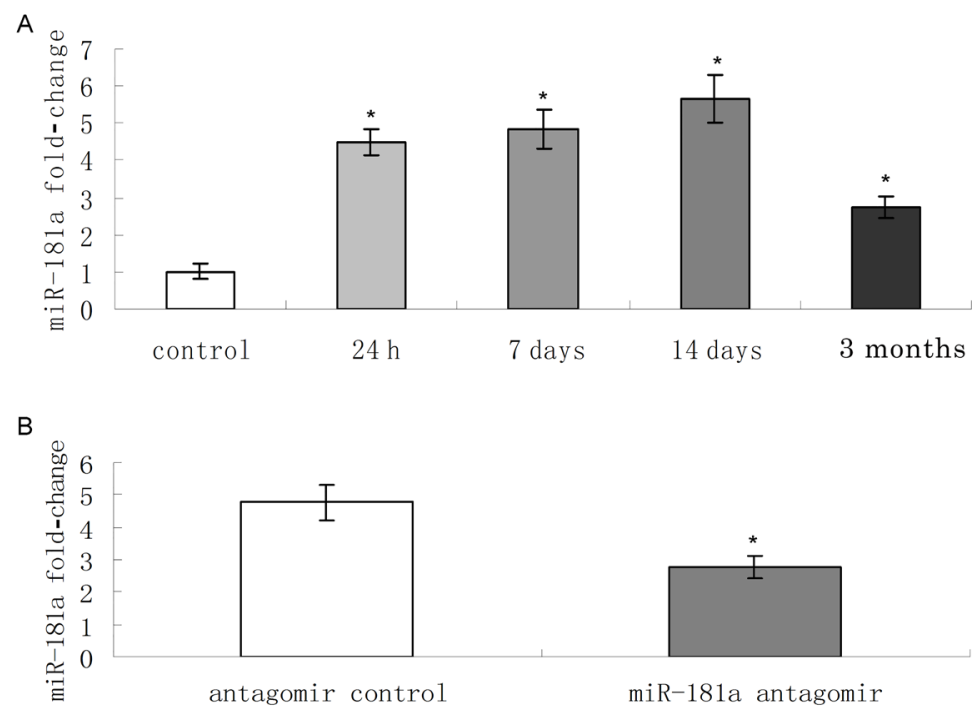

Figure 2. miR-181a expression post-SE and antagomir outcomes. A. Expression pattern of miR-181a. The study time points were 1 day, 1 week, 2 weeks (post-SE) and 3 months (temporal lobe epilepsy (TLE)). miR-181a shows increased expression at all four time points, when compared to its control group. B. Results of the miR-181a antagomir experiment. Displayed here is the miR-181a expression after miR-181a antagomir treatment 7 days post-SE in the rat hippocampus. The results show that the miR-181a antagomir has significantly inhibited the expression of miR-181a in the post-SE rat hippocampus when compared to the antagomir control. ${ }^{*} \mathrm{P}<0.05$, compared to control. $\mathrm{N}=10$ for each experimental group. 


\section{Alteration of activated caspase-3 expression}

Figure 3 presents the results from the qRT-PCR and western blot for the expression of caspase- 3 and -9 in the post-SE rat hippocampus. Significant differences in the up-regulation were discovered in the expression of activated caspase-3 (3.28 \pm 0.38$)$ and caspase-9 $(3.44 \pm 0.40)$ at 7 days post-SE in the rat hippocampus $(P<0.05 \mathrm{~N}=10)$. This expression significantly decreased in the miR-181a antagomir-treated group $(2.25 \pm 0.28)$ compared to 7 days post-SE group and the antagomir control group $(P<0.05, N=10$ ) (Figure $3 A$ ). Results from the western blot analysis confirmed the drastically decreased activated caspase- 3 and -9 protein expression level in the miR-181a antagomir-treated group (Figure 3B).

A

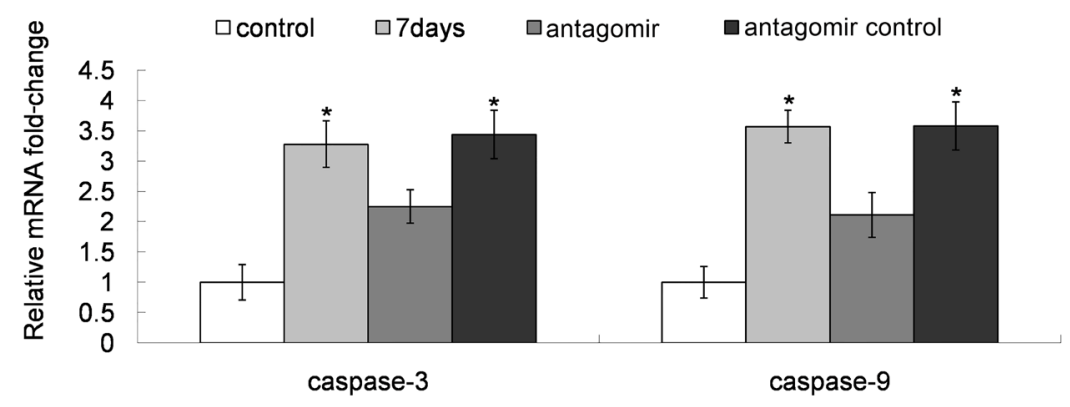

B

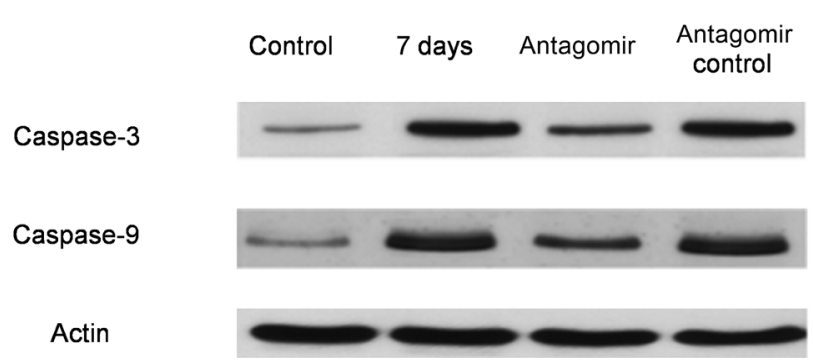

Figure 3. Activated caspase-3 expression and protein in the post-SE rat hippocampus. A. Significant differences in the expression of activated caspase- 3 at 7 days post-SE in the rat hippocampus. This expression significantly decreased in the miR-181a antagomir-treated group compared to the 7 days post-SE group and the antagomir control. B. Representative blot from the western blot analysis shows up-regulation in the expression of activated caspase-3 protein 7 days post-SE in the rat hippocampus, when compared to control, and drastically decreased activated caspase-3 protein expression level in the miR-181a antagomir-treated group. ${ }^{*} \mathrm{P}<0.05$, compared to control. $\mathrm{N}=10$ for each experimental group.

\section{Alterations in neuronal death}

From Figure 4A-D, it can be seen that the portion of the brain affected by neuronal death increased in the post-SE rat hippocampus. miR-181a antagomir treatment decreased the seizureinduced neuronal death in the hippocampus of post-SE rats in the regions CA1 (Figure 4E-H) and CA3 (Figure 4I-L) compared to the control group at 7 days post-SE. 

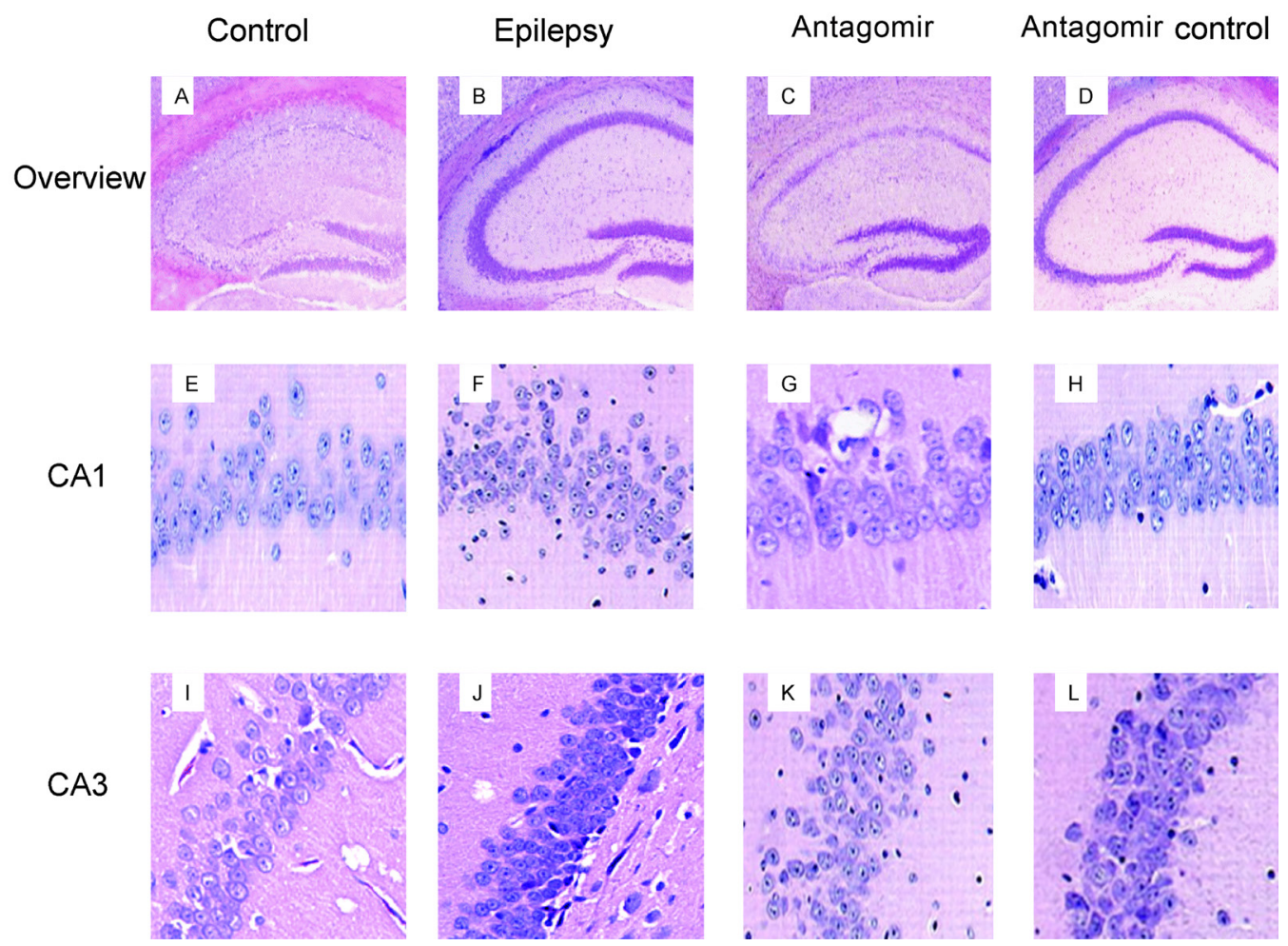

Figure 4. Apoptosis visualized using the TUNEL assay in the post-SE rat hippocampus samples. A.-D. Overview of the hippocampus; E.-H. Cornu ammonis 1 region (CA1); I.-L. Cornu ammonis 3 region (CA3). Scale bars: 200 mm (A-D), $20 \mathrm{~mm}$ (E-L). TUNEL-positive cells are defined as those with blue-purple nucleic staining.

\section{DISCUSSION}

Five brain enriched miRNAs, miR-132, miR-146a, miR-181a, miR-34a, and miR-124, showed increased expression in the epilepsy tissue samples, with the greatest changes occurring for miR-181a. miR-181a was also remarkably increased in the lithium chloride stimulation model brain samples at 3 months. These results were in accordance with previous studies in this field. Nudelman et al. (2010) observed an increased miR-132 expression at $8 \mathrm{~h}$ in the pilocarpinestimulated mice hippocampus. Aronica et al. (2010) found miR-146a to be up-regulated in epilepsy. Peng et al. (2013) reported on the potential role of increased miR-124 in TLE and in cell proliferation. Moon et al. (2013) investigated the role of miR-181a throughout the course of neuronal injury in vitro and hippocampal neural loss in vivo after forebrain ischemia. They found that miR-181a expression was increased when patients underwent forebrain ischemia. The level of expression of miR-34a has also been found to be regulated in a variety of animal epilepsy models (Hu et al., 2012). Along with this, the expression of miR-34a has been linked to neuronal apoptosis in the hippocampus. One of the primary findings of this study was the significant correlation between the expression of miR-181a and the activity of an indicator of cellular apoptosis called caspase-3. Another important finding from this study was that the expression of miR-181a showed significant increases both in rat models as well as in TLE patient samples post-SE. The miR-181a antagomir 
effectively reduced the levels of both miR-181a and CA1 neuronal apoptosis. The findings of this study suggests that miRNA-181a participates in the pathogenesis of chronic TLE by regulating the rate at which neuronal apoptosis occurs in the hippocampus. Earlier research has shown that miR181a has been related to a wide range of cellular processes including, but not limited to, cell fate determination and cellular invasion (Liu et al., 2013).

miR-181a is found in large quantities in the brain. The inhibition of miR-181a is related to the reduction of astrocyte death in vitro as well as infarct volumes after stroke in vivo. Saba et al. (2012) were the first to report that miR-181a showed significant down-regulation in primary glioblastomas and human glioblastoma cell lines compared to regular human tissue. They established that miR181a functioned not only as a tumor suppressor, but also played a role as a growth inhibitor, apoptosis inducer, and inhibitor of the invasion of adjacent glioma cells. The down-regulation of miR-181a may be a relevant factor contributing to malignancy in human gliomas (She et al., 2014). Ouyang et al. (2012) manipulated the levels of miR-181a in astrocyte cultures by using inhibitors and mimics. They found that the reduction of this miRNA was linked to increased levels of Bcl-2 and $\mathrm{Mcl}-1$ proteins. They showed that the falling levels of miR-181a leads to reductions in glucose deprivation-induced apoptosis, mitochondrial dysfunction, and loss of mitochondrial membrane potential in astrocytes.

In previous research, apoptosis has been related to neuron loss in chronic TLE as well as brain damage (Henshall and Simon, 2005; Lewis, 2005; Li et al., 2014a,b).This study has shown that chronic TLE increases the number of apoptotic neurons in the rat hippocampus. The current findings support those of Hu et al. (2012) who found that apoptosis represented part of the mechanisms underlying the chronic TLE-induced neuronal loss. It is possible to trigger chronic TLErelated apoptosis by activating certain intrinsic pathway components, which include pro-apoptotic proteins belonging to $\mathrm{Bcl}-2$ and other members of the caspase family. In addition, previous studies have shown that neuronal apoptosis can effectively be triggered by the activation of an extrinsic pathway (Henshall, 2007; Fernandes et al., 2011). As mentioned earlier, it is unknown how many varying functions miRNAs may have in the hippocampus of animals experiencing induced epilepsy. An antagomir is a stable and locked nucleic acid. It is an engineered RNA oligonucleotide, which has the ability to recognize based on sequence complementarities, a specific miRNA and induce its degradation process (Dogini et al., 2013). These molecules are valuable tools when it comes to probing the functions of miRNAs in vivo. In fact, functional studies have been conducted with epilepsy animal models in the past (Jimenez-Mateos et al., 2011). Earlier studies have established that miR132 is down-regulated within a mouse's CA3 subfield after undergoing seizure pre-conditioning (Jimenez-Mateos et al., 2011). In that same study, the authors administered an antagomir to the intra-cerebroventricular portion of the brain. The consequence of this administration was the reduction in expression of miR-132, which led to the reduction of neuronal loss in the hippocampus of SE mice. Down-regulation of miR-34a was observed with intra-cerebroventricular injections of antagomir to the hippocampus in the lithium-pilocarpine epilepsy model (Hu et al., 2012). A similar injection had no effect in the intra-amygdala kainic acid injection model in mice. Differences in experimental outcomes can be attributed to a variety of factors not limited to differences in the mouse species, models, or time points analyzed (Krützfeldt et al., 2007).

In conclusion, our results demonstrated the increased expression pattern of five miRNAs in patients with epilepsy and post-SE rats. Our study also provided evidence that the inhibition of miR-181a exhibited a neuroprotective effect on seizure-induced neuronal apoptosis. These findings suggest that the expression alteration of certain miRNAs may be associated with epilepsy 
status and indicate the protective effects of targeting specific miRNA against neuronal apoptosis, which may open up new avenues in treatment of refractory epilepsy.

\section{Conflicts of interest}

The authors declare no conflict of interest.

\section{ACKNOWLEDGMENTS}

We want to acknowledge the evaluators, research assistants, and particularly the adolescents and families who participated in this study.

\section{REFERENCES}

Aronica E, Fluiter K, Iyer A, Zurolo E, et al. (2010). Expression pattern of miR-146a, an inflammation-associated microRNA, in experimental and human temporal lobe epilepsy. Eur. J. Neurosci. 31: 1100-1107. http://dx.doi.org/10.1111/j.1460$\underline{9568.2010 .07122 . x}$

Arzimanoglou A, Hirsch E, Nehlig A, Castelnau P, et al. (2002). Epilepsy and neuroprotection: an illustrated review. Epileptic Disord. 4: 173-182.

Ashhab MU, Omran A, Kong H, Gan N, et al. (2013a). Expressions of tumor necrosis factor alpha and microRNA-155 in immature rat model of status epilepticus and children with mesial temporal lobe epilepsy. J. Mol. Neurosci. 51: 950-958. http://dx.doi.org/10.1007/s12031-013-0013-9

Ashhab MU, Omran A, Gan N, Kong H, et al. (2013b). MicroRNAs (9, 138, 181A, 221, and 222) and mesial temporal lobe epilepsy in developing brains. Transl. Neurosci. 4: 357-362. http://dx.doi.org/10.2478/s13380-013-0128-z

Bartel DP (2009). MicroRNAs: target recognition and regulatory functions. Cell 136: 215-233. http://dx.doi.org/10.1016/j. cell.2009.01.002

Berg AT, Vickrey BG, Testa FM, Levy SR, et al. (2006). How long does it take for epilepsy to become intractable? A prospective investigation. Ann. Neurol. 60: 73-79. http://dx.doi.org/10.1002/ana.20852

Dogini DB, Avansini SH, Vieira AS and Lopes-Cendes I (2013). MicroRNA regulation and dysregulation in epilepsy. Front. Cell. Neurosci. 7: 172. http://dx.doi.org/10.3389/fncel.2013.00172

Fernandes MJS, Cavalheiro EA, Leite JP and Persike DS (2011). Temporal lobe epilepsy: cell death and molecular targets, underlying mechanisms of epilepsy. (Kaneez FS, ed.). In Tech, DOI: 10.5772/19835; ISBN: 978-953-307-765-9. Available from: http://www.intechopen.com/books/underlying-mechanisms-of-epilepsy/temporal-lobe-epilepsy-cell-deathandmolecular-targets.

Hauser WA (1995). Epidemiology of epilepsy in children. Neurosurg. Clin. N. Am. 6: 419-429.

Henshall DC (2007). Apoptosis signalling pathways in seizure-induced neuronal death and epilepsy. Biochem. Soc. Trans. 35 : 421-423. http://dx.doi.org/10.1042/BST0350421

Henshall DC and Simon RP (2005). Epilepsy and apoptosis pathways. J. Cereb. Blood Flow Metab. 25: 1557-1572. http:// dx.doi.org/10.1038/sj.jcbfm.9600149

Hu K, Xie YY, Zhang C, Ouyang DS, et al. (2012). MicroRNA expression profile of the hippocampus in a rat model of temporal lobe epilepsy and miR-34a-targeted neuroprotection against hippocampal neurone cell apoptosis post-status epilepticus. BMC Neurosci. 13: 115. http://dx.doi.org/10.1186/1471-2202-13-115

Huttenlocher PR and Hapke RJ (1990). A follow-up study of intractable seizures in childhood. Ann. Neurol. 28: 699-705. http://dx.doi.org/10.1002/ana.410280516

Jallon P (2002). Epilepsy and epileptic disorders, an epidemiological marker? Contribution of descriptive epidemiology. Epileptic Disord. 4: 1-13.

Jimenez-Mateos EM, Bray I, Sanz-Rodriguez A, Engel T, et al. (2011). miRNA Expression profile after status epilepticus and hippocampal neuroprotection by targeting miR-132. Am. J. Pathol. 179: 2519-2532. http://dx.doi.org/10.1016/j. ajpath.2011.07.036

Jimenez-Mateos EM, Engel T, Merino-Serrais P, McKiernan RC, et al. (2012). Silencing microRNA-134 produces neuroprotective and prolonged seizure-suppressive effects. Nat. Med. 18: 1087-1094. http://dx.doi.org/10.1038/nm.2834

Krützfeldt J, Kuwajima S, Braich R, Rajeev KG, et al. (2007). Specificity, duplex degradation and subcellular localization of 
antagomirs. Nucleic Acids Res. 35: 2885-2892. http://dx.doi.org/10.1093/nar/gkm024

Lewis DV (2005). Losing neurons: selective vulnerability and mesial temporal sclerosis. Epilepsia 46 (Suppl 7): 39-44. http:// dx.doi.org/10.1111/j.1528-1167.2005.00306.x

Li MM, Jiang T, Sun Z, Zhang Q, et al. (2014a). Genome-wide microRNA expression profiles in hippocampus of rats with chronic temporal lobe epilepsy. Sci. Rep. 4: 4734.

Li MM, Li XM, Zheng XP, Yu JT, et al. (2014b). MicroRNAs dysregulation in epilepsy. Brain Res. 1584: 94-104. http://dx.doi. org/10.1016/j.brainres.2013.09.049

Liu Y, Zhao Z, Yang F, Gao Y, et al. (2013). microRNA-181a is involved in insulin-like growth factor-1-mediated regulation of the transcription factor CREB1. J. Neurochem. 126: 771-780. http://dx.doi.org/10.1111/jnc.12370

Livak KJ and Schmittgen TD (2001). Analysis of relative gene expression data using real-time quantitative PCR and the 2(-Delta Delta C(T)) Method. Methods 25: 402-408. http://dx.doi.org/10.1006/meth.2001.1262

McKiernan RC, Jimenez-Mateos EM, Sano T, Bray I, et al. (2012). Expression profiling the microRNA response to epileptic preconditioning identifies miR-184 as a modulator of seizure-induced neuronal death. Exp. Neurol. 237: 346-354. http:// dx.doi.org/10.1016/j.expneurol.2012.06.029

Moon JM, Xu L and Giffard RG (2013). Inhibition of microRNA-181 reduces forebrain ischemia-induced neuronal loss. J. Cereb. Blood Flow Metab. 33: 1976-1982. http://dx.doi.org/10.1038/jcbfm.2013.157

Nudelman AS, DiRocco DP, Lambert TJ, Garelick MG, et al. (2010). Neuronal activity rapidly induces transcription of the CREBregulated microRNA-132, in vivo. Hippocampus 20: 492-498.

Omran A, Elimam D, Shalaby S, Peng J, et al. (2012a). MicroRNAs: a light into the "black box" of neuropediatric diseases? Neuromolecular Med. 14: 244-261. http://dx.doi.org/10.1007/s12017-012-8193-y

Omran A, Peng J, Zhang C, Xiang QL, et al. (2012b). Interleukin-1 $\beta$ and microRNA-146a in an immature rat model and children with mesial temporal lobe epilepsy. Epilepsia 53: 1215-1224. http://dx.doi.org/10.1111/j.1528-1167.2012.03540.x

Ouyang YB, Lu Y, Yue S and Giffard RG (2012). miR-181 targets multiple Bcl-2 family members and influences apoptosis and mitochondrial function in astrocytes. Mitochondrion 12: 213-219. http://dx.doi.org/10.1016/..mito.2011.09.001

Peng J, Omran A, Ashhab MU, Kong H, et al. (2013). Expression patterns of miR-124, miR-134, miR-132, and miR-21 in an immature rat model and children with mesial temporal lobe epilepsy. J. Mol. Neurosci. 50: 291-297. http://dx.doi. org/10.1007/s12031-013-9953-3

Saba R, Störchel PH, Aksoy-Aksel A, Kepura F, et al. (2012). Dopamine-regulated microRNA MiR-181a controls GluA2 surface expression in hippocampal neurons. Mol. Cell. Biol. 32: 619-632. http://dx.doi.org/10.1128/MCB.05896-11

Sano T, Reynolds JP, Jimenez-Mateos EM, Matsushima S, et al. (2012). MicroRNA-34a upregulation during seizure-induced neuronal death. Cell Death Dis. 3: e287. http://dx.doi.org/10.1038/cddis.2012.23

She X, Yu Z, Cui Y, Lei Q, et al. (2014). miR-181 subunits enhance the chemosensitivity of temozolomide by Rap1B-mediated cytoskeleton remodeling in glioblastoma cells. Med. Oncol. 31: 892. http://dx.doi.org/10.1007/s12032-014-0892-9

Tan CL, Plotkin JL, Venø MT, von Schimmelmann M, et al. (2013). MicroRNA-128 governs neuronal excitability and motor behavior in mice. Science 342: 1254-1258. http://dx.doi.org/10.1126/science.1244193 